\title{
成质歐美资產階級間者的“火葉 是歐洲人所發明”的語論
}

\author{
馮家昇
}

（中央民族學院研究部）

19 世紀以來，吹莱资座階級學者們以篇火䒚 的渡現與股在軍事學史上是劃時代的一俳事, 所以他們首先是一致的和歐洲以外的國家孚發現 與明的光榮帽子; 聯而他們內部發生了矛盾, 各自第日耳曼、拉厂、㳑格魯落克活系的國家互 爭火䒚、火器始用的先進美譽。篇了欲達到他們 证安的目的, 他們竟無恥的割裂史料, 鲳昧史料, 担造史料, 簡直是荒唐之至!

他們有的以篇歐洲交化是十全十美, 現代沟

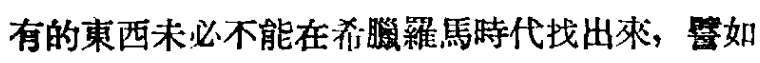
L. 拉克邦和 M. 具再特特就是這一派的代表。貝 爾特露以篇東程馬人所用的“乔䐳火”是變名的火 柴, 衰頭有硝。1870-1871 年, 普法之戰, 德軍 圍攻巴黎日以千數“乔䱋火”砲彈射入城中。他以

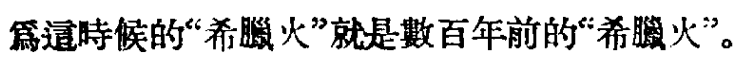
他以篇 19 世紀的“希䱋火”裏有硝, 遂武断门古 時代的“希胭火”也有硝。拉克邦則以第真让的

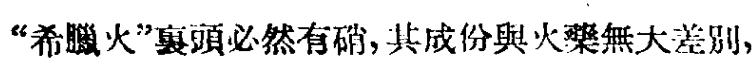
中古時代篇唒洲人所遺忘。他簡直是猜想! 現在 我們知道“希腅火”、“石油機”與“火䒚”這三種東 西的成份䊅對不同: “希䐳火”很簡單, 只有硫磺 及其他燃邺性的物留，但釈没有硝; “石油機”以 石油篇主體，而又附加好幾種碳油與油脂; “火 莱”是以硝、碳、炭第主，有時量有其他質料。

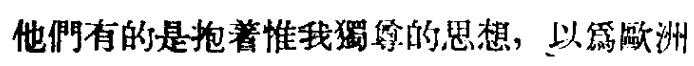
没有某一件束西，那末世界上任何地方也就不會 有了。19世紀 40 年代至 70 年代法偉和拉努学拿 破菕第三所御用, 編“過去與將隶火砲的研究”

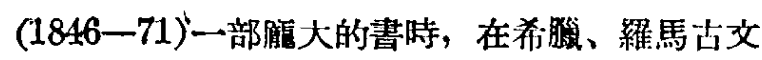
書裏左找右找而終找不出硝的踪跡来，很學得迹
氣, 竞大胆的室作說 13 世紀以前世界任何國家没 有硝。後來從 13 世紀中期的阿拉伯抄本中找得 硝的線荣, 名叫“中國雪” (telğa-s-Sin, ), 於是 他們才承認 13 世紀中國的确傳入阿拉伯。至於 硝在中國發現了多久, 他們也就不問了。

承認中國先有硝不等於承認中國先有了火

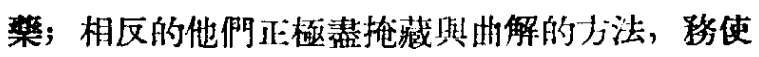
火蓧的發明歸到臤洲人的頭.上。他們利成了天主

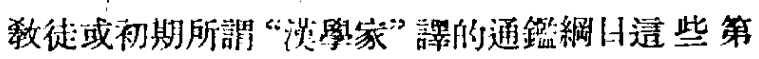
二、三流材料, 說 $1.232-1233$ 年㭬一人攻開封 時, 中國人所用的重要讯器“飛火榆”和“震天雷”

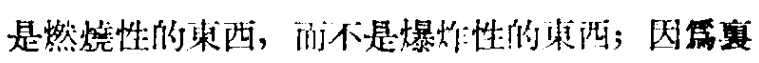
頭没有硝。何以知近呢? 他們說不计理由東, 因 第他們沟有能力庴搜中國的材料。，但即使咃們有 此能力, 他們也不肯做, 刏篇他們预先早已定好

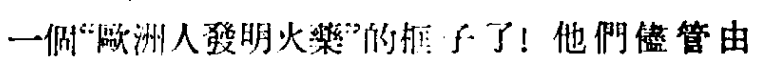
阿拉伯计畫中，找 4 个“契丹火箭”(Sahm Xatai) 的火架成份是: (1) 硝 10 雨, 水炭 $2 \frac{5}{8}$ 兩, 硫碳

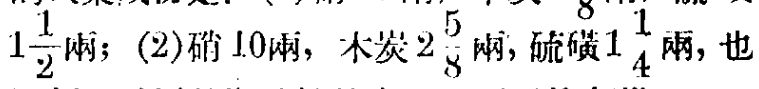

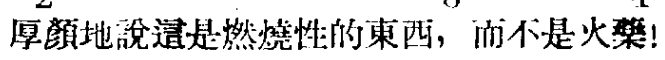

還有一種阿拉伯捛是 14 愢紀初的產物, 他們

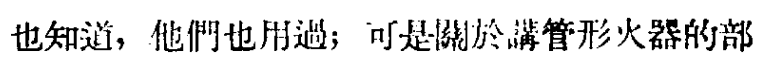
份, 他們却故意隐藏起來不提。这種! 管形火器

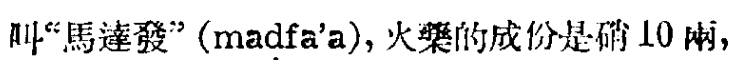

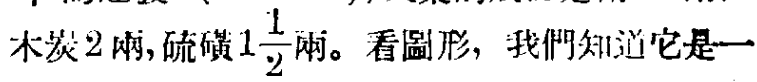

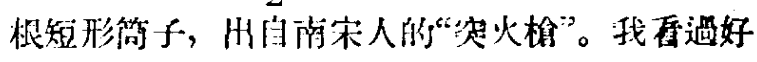

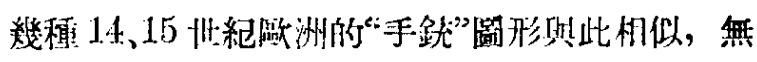

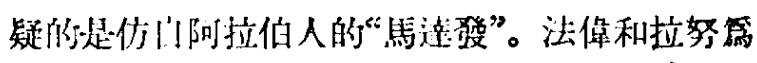

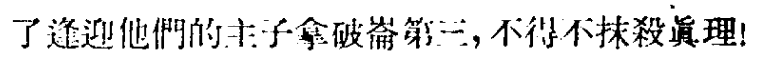
不得不隐藏起透湺真理的材料! 


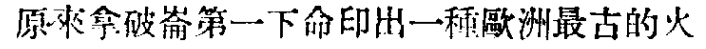

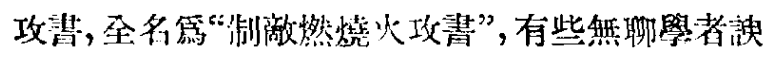

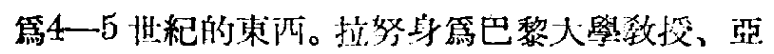

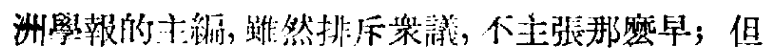
他却不敢或作保急指出那是變相的一本阿拉伯

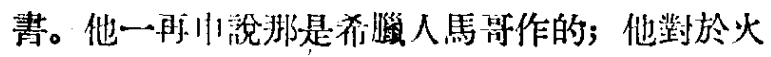
蔡的絬論是: 中國最先用硝, 阿拉伯人㘿先用帶

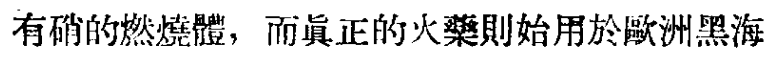
沿岸及多惱河下流地區。至於火器, 則先用於拉 丁系的意大利, 因篇意大利詩人格斗 - 加屋跐康 替一当詩: “你留心一一我說, 你留心! 守衛好,

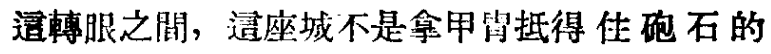
呀! ”是提到火硕的。據說這首詩寫於 1299 年。可 是讀了這首詩後, 任何人看不出火砲的意思是在 那裏。所說砲石 (bombarde) 如 artillerie一樣, 在中古和古代均是指执石機, 㛑砲而言, 决不是 後日的管形火器。此點拉克邦已早在 19 世紀 40 年 代說過, 而拉努和法愇亚非不知。其所以明知其 非而故意拾出來的線故, 無非藉以搪塞能了。後 日的火䒚史家們也沟有再重的完它。

拉努和法偉第了得他們主人的歡心，誇耀拉 丁系國家的創造能力, 不惜隱藏史料, 曲解史 料, 以謀掩盡天下人的耳目。但事不作美, 就有 些調皮學者起來揭穿其酸惡，M. 開德美就是其中 之一。開德美在當時是阿拉伯文、波斯文的權 威，他於1836年譯完一部份拉施德“集史”，並編 譯過伊賓開敦的集子，對火樂方面的材料也相當 熟替。他主偯中國和阿拉伯先用火藥火器, 而反 對歐洲發明火䒚的說法。他並且着重的指出“在 13 或 14 世紀的前期，我們在西文書中找不出一 個字表示我們應书火器及以火䒚發射 東西”。然 後他又把拉努和法偉二人的譯交逐们 批評了一 下. 邆簡直對拉努是一佔重大的打繁。拉努怕

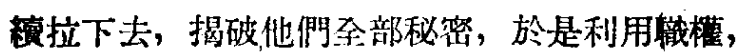
在 “亞洲學報” 特登出啓事說: “因篇篇幅所限, 此問題的对論以此篇止; 本報以後不能再登此類 文字”。

經過薑一回波折, 拉努和法偉踓然拒稆承認 中國先用火樂之詮，但不得不承認阿拉伯八用火 棐及火器先於歐洲人。因第俄國聖彼得堡所藏 14 世䄫初期的一種阿拉伯抄本已早篇人所共知, 那 真頭記載着阿拉伯管形火器, 蓝有圖形可資證明。
可是1871年版的“過去與將來火砲的研究”一部

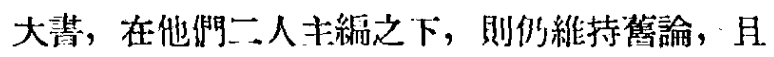
圖版中世沒有把阿拉伯行管形火器給印_上!，一些 學者先生們高唱學盛獨许與自由; 但每每篇統治 階級所御用與收買, 其意志與䝠紫不低不能獨立, 不但不能自由, 而且常在挾持之下，作了統治階 級意志與願崖的一部份。拿破嵛第三時縟火桨火 器史的這些人就更足以證明。

德國火棐史家大致承認中國先用火樂, 但他 們篇材料限制, 流於武斷, 竟說是中國後來忘了。 䇾如拉毛基引用了中國好幾種史料, 甚至把“宋 史”兵志叙述“乫火㭘”的一段原文印上並譚化來。 但到後來他找不到關於中國有用火森的事该時, 則武斷的說中國後來把它忘了。16世紀歐洲人來 中國時,一致認篇中國人不認識火器。真是胡㔔! 我們的湖先從第 9 世紀發現火樂後, 人一直在步步

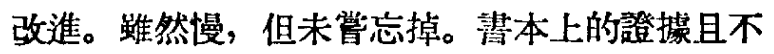
提, 試看南通博物館藏的 1356 和 1357 年张士誠 的長形大砲, 太原博物館藏的 1377 年洪 让冲天 砲, 北京想史博物館藏的洪试“金鍮”，燕京大舉 藏的洪武竹節手銃, 北京博物館又藏一種1426年 宣德銅砲。邆些都是16世紀以前歐洲人還没來, 而我們祖先已經能製造這樣優良的火器了。

他們踓然承認中國先用火樂, 但他們没有能 力證明，或不願意承認殹洲的火䒩是原於中國。 他們以篇德國的火樂知識是出自大亞力奍爾特, 而大亞力卑㕣特则又原於杀胋人馬哥。繁如拉得 根說, 在德國福筒克稫爾特城 1.348 年的記速上,

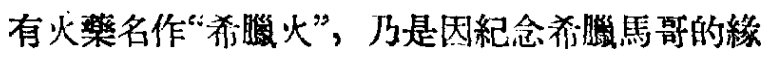
故。15世紀的書中提到 B. 失娃子是希臉人，也

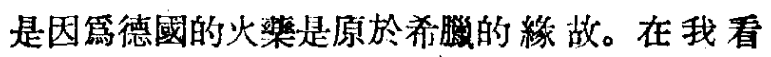

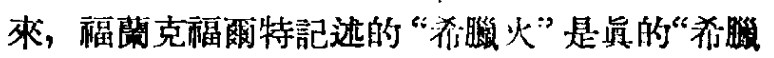
火”而不是火藥, 與希臘馬呩無關。歐洲中古文 書說“乔䐝火”者多㚐，豈皆得謂之紀念乔臙馬 哥? 失娃子是倜榊話中的人物: 有的說他是意大 利人，有的說是丹娄人，有的說是德國人，有的 說是希脸人; 其䝷他不是任何國的人，也没有發” 明過火䒩或火器。拉得根說他發明迥冲天砲要是

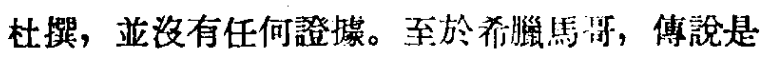

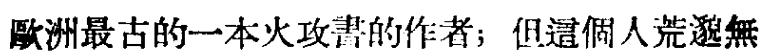

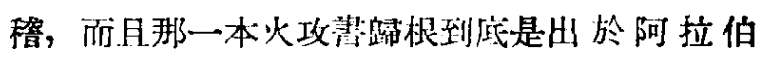
書。我在前篇已詳篇論證(進步日報1951年11月 
30 日史學通刊), 今不重逝了。

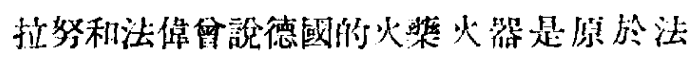
國; 拉得根力蚱其非, 與出12 程材料, 其中只有 兩種是指法國的火箭。這也許是對的, 因䉆拉努 和法偉編印“過去與將來火砲的研究”時, 正是 普法之戰。一時篇狹手的愛國主義所衝動, 亦未 可知。不過, 拉得根强調柧波羅那 1338 年之戰,

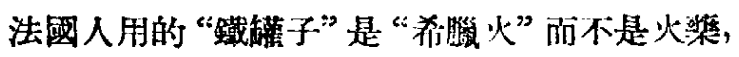
则不盡然。㨜拉克邦“論火䑁及 14 世紀傳入法國 考”後附的 13 種檔策看來, 那時候法國人用一磅 硝，牛磅活硫碏，數量踓然少，但也是一種火整。 那種 “鐵蠸子”好㑇金史上的“震天雷”, 效用在 炸毁, 而不在燒灼。用現在的話說, 是一種 “地 雷”或炸彈。它絕不能和只在燃燒沙 “希䱋火” 相比, 则可以断言。至於遭 “鐵堆子” 的來源很 長, 它是源於阿拉伯的瓶形火器, 而這種瓶形火 器则又源出於中國的“践炮”或“震天雷”。此點 賞再發揮, 今且略而不論。

海姆是個症狂的“倍根發明火萂論”者。篇 了支持其妄說, 他弿過雨本書, 好幾篇文章。在

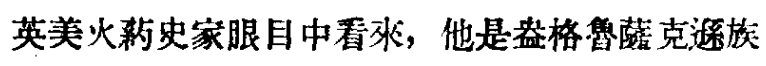
光榮的維護者。民說一出, 不但所謂火耘史專家 們附和之，而普通應用们 “大英百科全書” 從 11 版到 14 版, 均採用之。一值到 1948 年芝加哥新 版中, 才去掉不用。那就是說, 他的安說差不多 影㛒了學術界牛世紀之久!

第了拾一頂發明火新的光榮帽子加在益格魯

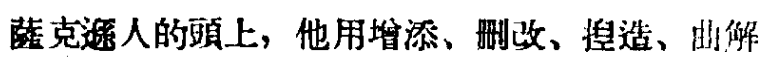

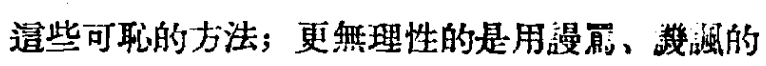
口吻對待河洲以外的國家。這個人十足表現仕資 産階級代言人的無恥與無聊!

他引證天主数徒馮秉正(Father Moyria de Maillac）的話，說中國人欺詐下流，没有機荘 天才，没有化學的創造; 即使有一點也是被吸收 於别方面了。所以他不承認中國有發明火茢们能 力; 甚至有火䒬以後, 也不能對製造方面有什染 進步與改良。他對中國歴史家踓没有批評, 但济 是別有用意的; 其用意在證明中國歴史家從來 没有宣份淍中國發明火来的論調。所以他說中國

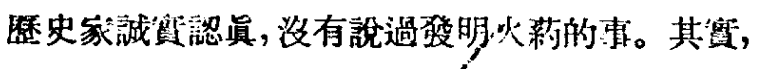

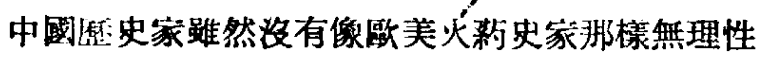
的孚搶誰先發明，但他們也有些論說。較其年代，

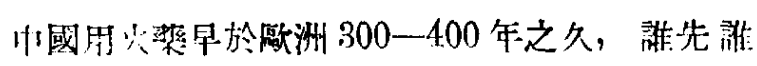

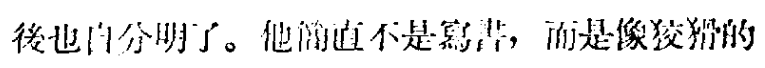

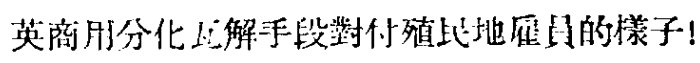

他知道 13 世紀以前歌洲沒有硝, 即武断的 說世界任何或家也没有, 中㖥所存的是些監碱之 類的東西。他不能說没有看胃拉努和法偉、拉毛 基這些人的整和文章: 但他是吸取於他有利的部 份; 凡與他的說法不合的，一概抹殺。他想把融 洲大陸火約史家們所得中國先用硝的結論推翻。

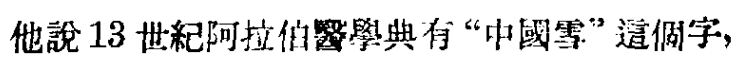
不能登明中國先有硝, 此力說, 䎼誕節防的火 鶏 turkey，和十:耳其 Turkey 是一個字，豈能

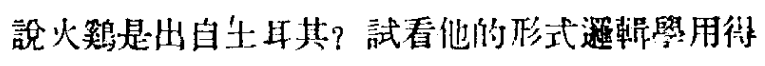
多妙! 要知道 turkey 是闹單词, talǧa-s-Sīn 是個衫合字，紹不能相此。而且波浙阿拉伯字的 構造, 凡是一種東西指明出自中國, 就加 $S \bar{i} n \overline{1}$ 或 $\operatorname{Sin}$ ，等如“中國矛”作 Xar-Sini，“中國柿子”

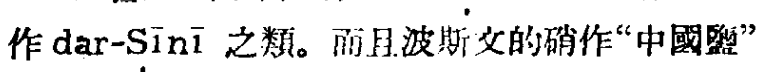
malaha-s-Sinni, 亦和 “中国雪” 的意思相同。 同時，那话火鴙的字與七耳其也不無關係。試一一

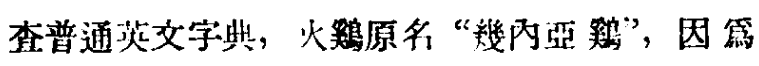
由非洲經土耳其倲入歐洲而名日 tur-key。如此 看來，那倜阿拉伯文的“中國等” 是有來璴的。

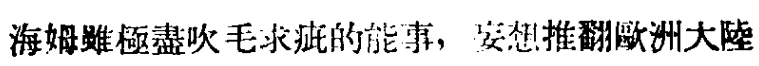
火萂史家的絬論, 是不可能的。

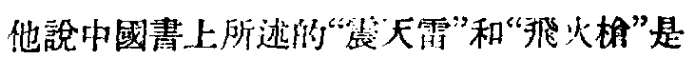
然燒性的東西而不是火萂集的。所說“其㛑如雷, 聞百里外，所熱圍平胡之上.”是等大，即任何大 火, 亦可 “大蹈如雷”, 不必火萂如是。然而“人

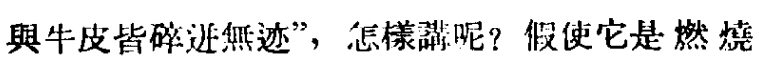
性的j，它應當是把“人與牛皮紫邺好然迹”，何以 說“碎迸無迹”呢？造明河是爆炸的結果。海姆筑 了欲符合其目的而目睡解能了。他說中國的燃烧性

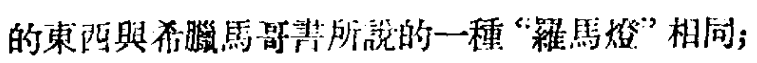
至於所謂火彩是 “将來的火湖”。他的絬論是 “中 国第一次從西洋獾得火新期火器”。不能廣搜中 或史料，倒不必怪他，因第他不是倜“嫨學家”。 第什璴浬拉努和法偉的樭和文章所記的“契丹火 箭”，“契外火輸”，“们国鐡”，“契丹花”也不

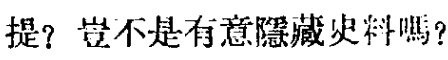

關於阿拉伯火粷與火器的史料, 他也一䇐的

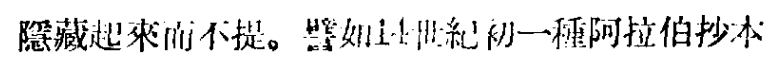


钎载一種管形火器叫“馬達發”，拉努和法偉在 “亞洲學報” 1849 年譯述過; 他不至於没有看墖; 因篇他熋引過他們在“严洲學報”，上的其他交章。 大梅管形火器火葋史家認第是自正的火器。有了 這一種火器, 表示火器史上有了一大進步, 人可

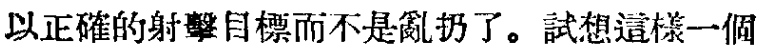
重大的發明, 以海姆的短見, 如何能不給隱藏起

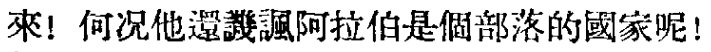

英國牛津敎堂藏的一種檔案, 上透是牧師給

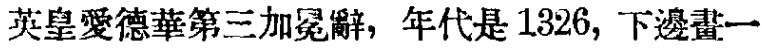
個瓶形火砲。據許多專家監定，上下的辭與圖不 是一個時代留的。海姆不問皇白, 竟大胆指第 1326 年的東西, 並且和干特所藏的一種橖案聯起 來。他說那種檔案是1313年提到火砲，而英國的 檔婪是1326年, 很可能的, 德國在那時候賣火砲 給英國。他蚘極盡猜測之能事! 據 C. 歌曼說:

一他於 1923 年 8 月適在干特城, 特意去看了一下 那種檔案, 原隶本交沒有提到火砲, 而在書邊上 有人添在 1319 年之下。添的人大概在 15-16 世

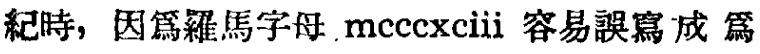
meccxiii。後來抄第的人又寫入 1313 年本文之 下。海姆想答倒法國 1338 年早用火䒬之事, 不情 拉早牛津火砲到 1326 年, 他的書和文內不提 德

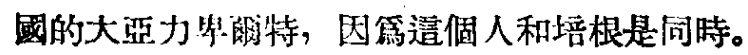
他既誉倍根搶走弡明火新的光榮帽子，乃將先用 火器的美名运給德國人。海姆的用心良苦㚐!

美國 G. 沙二百地像海姆一樣, 既不信中國

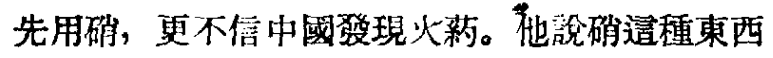
在熱帶地區比較多而繁明, 在寒帶地區则不然。 但問題要從兩點看: 一是某地虽是否雇硝? 二是 某地區是否認識硝? 認識比㦃生摆重要, 因第我 們如果認識了它, 即使在我們邉個地區不生党, 劻可以設法從生産的地區轉戝來。認識是否是硝 還不算，要在認識它的各種功用。南美智利是世 界上出座确的地區之一，但不能就說 500 年前的 印加封建王國已然有硝, 因第那時候印第安人根 本不認識那是什㦄東西。我們從紀元前 2 世紀, 已知硝在醫䒚和煉金術上的功用; 到了 5 世紀 後, 蓝能签别硝所以不同於朴硝在點着後發生青 焰; 9 世紀之頃, 認識了硝和其他成分, 偶爾發 現了火染。但目的亚不在殺人, 相反的, 乃在繁 浩長生不老藥, 治病救人。10世紀以後, 戈採用

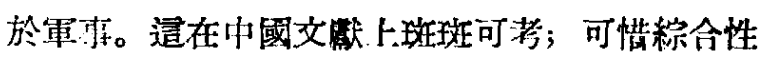
的科學史家沙二旦以及其他所謂候关 “漢學家” 未能廣搜這些材料!

至於火藥的發現, 沙二日歸之拉丁國家, 是 毫無根據的; 在他的文章裹也沒捉出任们理由。

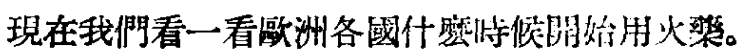

1. 法國 根據一種法文老檔, 在 1338 年 7 月 百年戰争之初, 法國的火樂火器極少。一封信上 說，一個將軍只接到一個鐵罐子，一僻础，牛磅活 硫磺。1345 年 4 月 29 日才有八磅火䒚的部践。

2. 英國 根據皇芜秘庫的一種檔案，1344年 12月25日至 1347 年 10 月 18 日，11月，爱德華 第三供給他的遠征軍硫磺和硝。

3. 德國 根據佛蘭哥芬爾特公用賑，1348年

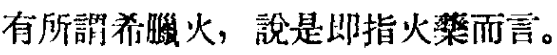

4. 俄國 根據俄國螎年史 Nikon 記载, 1382 年，金帳汗來攻莫斯科，守者用“體由發克”(tiufak）擊退之。這個“體由發克”是一種火器。

返看中國, 1040 年編成的武經總矮已有很完 備的火祭方子，一顆“毒樂烟毢”就 5 斤重。北 宋政府在開封開設工廠,大舅製造火綝。1232年， 金人有鐵擎 “震天雷” 擊退蒙古軍。1257 年, 李

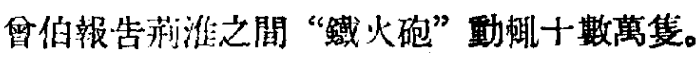

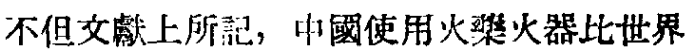
任何國早, 即在現 $/ j$ 的實物上說, 中國的火器此 世界任何國早而且多。

據美國沙二旦說歐洲最古的火器存於各地博 物館的僅 4隻: 1.1380 (伯恩愽物館)，2.1380 (福瑞爾博物館)，3.1395 (日耳暴博物館)，4. 1410 (勃賴爾博物館)。

中國古代火器你於今者䓕多, 摆其最古者如 下: 1.1356 (南通博物館)，2.1357 (南通博物 館)，3. 元銃 (北京大學文科研究所)，4.1372 (棐京大學), 5.1373 (南京博物館)，6.1377(太原 圖畫館)，7.1378(北京歴史博物館)，8.1379(北 京歴史博物館)。

元末明初火器遗留至今的, 不僅於此, 通不 過是隨手提出來的; 至於洪武以後的火器散見各 處甚多。前中央研究院曾稍事收集, 即達烧百尊,

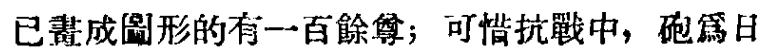
冦銷毁，圖形则不知失落何處！ 